\title{
Design of Small Dual Band Microstrip Antenna for Broadband Applications
}

\author{
R.S. Parbhane \\ SSGBCOET, Department of Electronics and Communication \\ Bhuswal, 425201, India \\ Email:parbhanerahul67@gmail.com
}

\begin{abstract}
In this article, a small dual band rectangular slot antenna for broadband application is presented. The antenna is being excited by capacitively coupled probe feed. The antenna consists of rectangular slot from the center of the patch. The rectangular slot is being used to obtain dual frequencies of $2 \mathrm{GHz}$ and $3.34 \mathrm{GHz}$.Instead of a rectangular feed strip, antenna is excited by a triangular feed strip with same dimension. Triangular feed strip is used to obtain a broad band frequency range. The size of the antenna is $100 \times 100 \times 1.6 \mathrm{~mm} 3$ with the ground of same dimension. The proposed antenna is simulated and optimized using IE3D simulation software.
\end{abstract}

Keywords: return loss, VSWR, FR4, Air Gap, SMA connector, MOM simulation, slotted microstrip antenna

\section{Introduction}

Today as the research is increasing day by day, so in high performance application such as aircraft, spacecraft, satellite and missile applications, where size, weight, cost, performance, ease of installation and aerodynamic profile are constraints low profile antenna is used. Microstrip antenna is being designed to work in broadband as well as narrow and wideband frequency range $[1,2]$. A slotted circular monopole antenna is presented [3] has spike shaped slots with square patch rotated around 45 degree to achieve ultra-wideband (UWB) applications.

Coplanar capacitively coupled microstrip antenna [4] is used for wideband applications with impendence bandwidth of 50\%.A printed Egg curved slot antenna[5]for wideband frequency range with gain of 4.1-5.1dBi. Many microstrip antennas which operate for dual and tri-band operation are being reported [6-11]. For example bandwidth enhancement of printed slot antenna [6] having wideband of 2.80 to $11.81 \mathrm{GHz}$ is reported. Antennas reported in [7] have a circular polarization with frequency ratio of 1.11 . On the other hand, the antenna in [8] offers for ultra wideband 
frequency band from $840 \mathrm{MHz}$ to $960 \mathrm{MHz}$ and [9] offers for maximum antenna bandwidth.

Antenna reported in [11] offers for a dual band frequency range for a dual square ring slot. Polarization is also main characteristics in design of antenna. Antenna in [12] offers for circular polarization with axial ratio (AR) below $2 \mathrm{~dB}$. Antenna proposed in $[13,14]$ have a slot along the patch to enhance for dual band operation. In the proposed antenna an air gap with dual band frequency with good bandwidth is being proposed

The basic geometry is shown in section 2. The design starts with the selection of center frequency and it may be scaled to any frequency of interest. Design and optimization procedure are shown in section 3. Sections 4 show the Experimental validation along with discussion. Conclusion of this study is shown in section 5 .

\section{Antenna Geometry}

The proposed antenna has a rectangular slot in vertical direction from center of the patch. Substrate used for design is FR4 with dielectric constant of 4.4 and thickness of $1.6 \mathrm{~mm}$ with air gap of $7.5 \mathrm{~mm}$. A long pin SMA connector is used to connect the feed strip which couples the energy to the patch by capacitive means. The detailed optimization procedure of the antenna and their optimum dimension characteristics are presented in section 3 .

The antenna was designed to operate with center frequency of $2.4 \mathrm{GHz}$. Rectangular antenna with rectangular slot with all physical parameter is shown in the Fig. 1. which is optimized with the IE3D [15] which is a method of moment (MOM) simulation software. The details dimensions of the optimized antenna are listed in Table 1.

$\mathrm{L}$

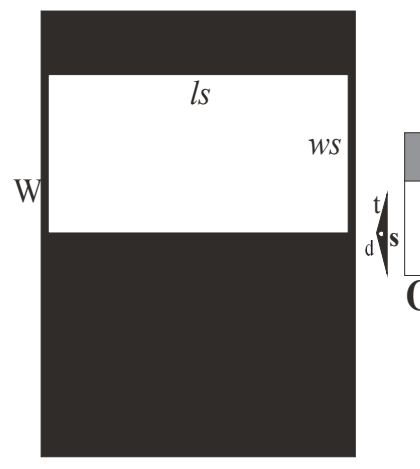

(a)

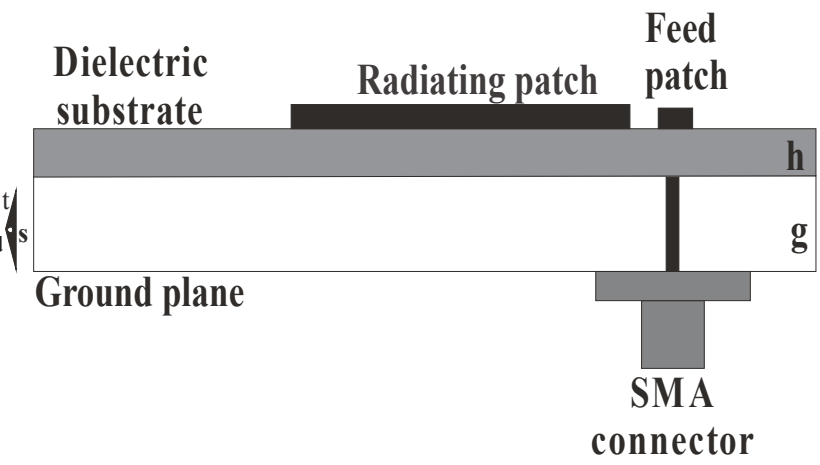

(b)

Figure 1. Geometry of patch antenna. (a) Top view (b) Cross sectional view 
Table1. Optimized dimensions of the proposed antenna

\begin{tabular}{|c|c|}
\hline Antenna Parameters & $\begin{array}{c}\text { Values with Air } \\
\text { Gap(mm) }\end{array}$ \\
\hline Length of radiator patch(L) & 42.0 \\
\hline Width of radiator patch(W) & 57.0 \\
\hline Length of feed strip(s) & 11.1 \\
\hline Width of feed strip(t) & 1.5 \\
\hline $\begin{array}{c}\text { Separation between feed strip from the } \\
\text { patch(d) }\end{array}$ & 0.5 \\
\hline Air gap(g) & 7.5 \\
\hline Slot length $(l s)$ & 40.0 \\
\hline Slot width $(w s)$ & 20.0 \\
\hline Slot position(p) (from center of patch) & 10.0 \\
\hline
\end{tabular}

\section{Geometry Optimization and Discussions}

The optimization process is shown in this section. The key design parameters used for the design are air gap, distance between radiative patch and feed, slot position, sloth width, and slot length. The details are given in the following subsections.

\subsection{Effect of Air Gap (g)}

As shown in Fig. 2., air gap of antenna is being varied from $6.5 \mathrm{~mm}$ to $11.5 \mathrm{~mm}$ in steps of $1 \mathrm{~mm}$. air gap (g) is used to maximize the antenna's bandwidth. Air gap of $7.5 \mathrm{~mm}$ is used to maximum bandwidth and maximum gain. As air gap changes, there is shift in the resonance frequency of the antenna. The upper frequency goes on increasing as we increase the air gap (g). From Fig. 2., it may be noted that the upper and lower cutoff frequency varies accordingly as the air gap change. From Table 2. it may be noted that maximum bandwidth is obtained at $1.92-3.52 \mathrm{GHz}$ frequency i.e $65 \%$ for the proposed geometry. As the air gap goes on increasing the bandwidth of proposed geometry goes on reducing. 


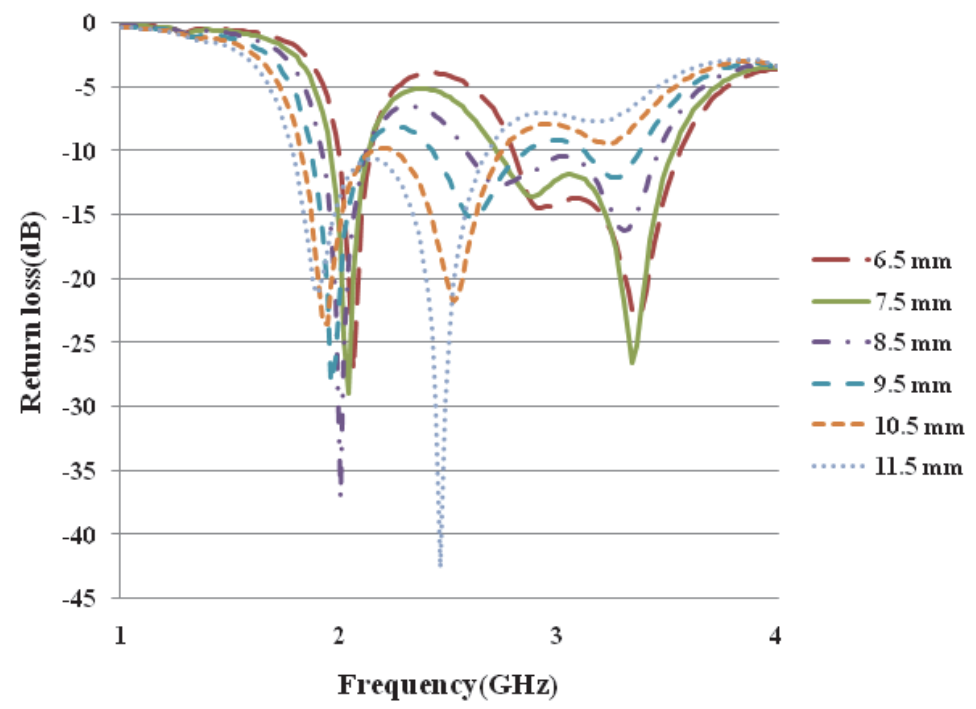

Figure 2. Return loss characteristics for different air gap.

Table 2. Effect of Variation of Air Gap on bandwidth of proposed antenna

\begin{tabular}{|c|c|c|c|c|c|c|}
\hline $\begin{array}{c}\text { Air Gap(g) } \\
(\mathbf{m m})\end{array}$ & 6.5 & 7.5 & 8.5 & 9.5 & 10.5 & 11.5 \\
\hline $\begin{array}{c}\text { Frequency } \\
\text { range (GHz) }\end{array}$ & $2-3.5$ & $1.96-3.52$ & $1.92-3.46$ & $1.88-3.38$ & $1.84-2.74$ & $1.8-2.66$ \\
\hline Bandwidth (\%) & 62.5 & 65.0 & 64.2 & 62.5 & 37.5 & 35.8 \\
\hline
\end{tabular}

\subsection{Effect of distance between radiator patch and feed strip (d)}

The distance between the patch and feed strip plays an important role in design of the antenna. It does not change the bandwidth of the antenna but shows a change in the depth of $\mathrm{S}_{11}$ parameter of the antenna. The distance between radiator and strip is change from $0.4 \mathrm{~mm}$ to $0.9 \mathrm{~mm}$ in steps of $0.1 \mathrm{~mm}$ each. The variation in $\mathrm{S}_{11}$ parameter of radiator patch and feed strip is shown in Fig. 3. From Fig. 3., it is clear that the lower cut-off frequency remains constant, only the upper cut-off frequency changes. From Table 3 it is clear that the optimum result for the distance with maximum bandwidth of $65 \%$ is obtained at $\mathrm{d}=0.5 \mathrm{~mm}$. 


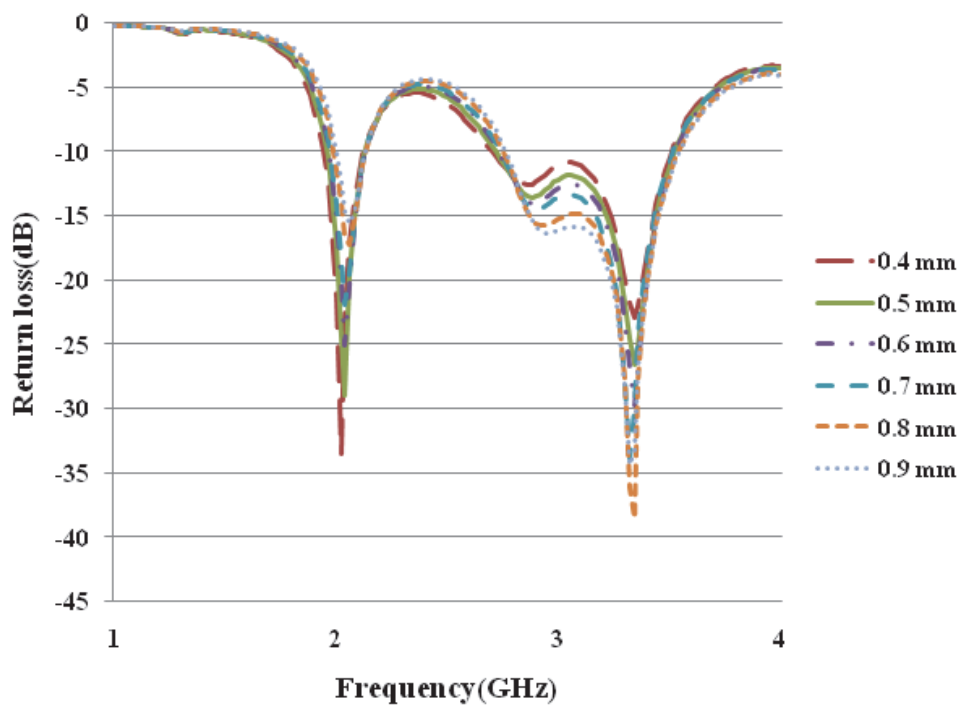

Figure 3. Return loss characteristics for different feed strip distance

Table 3. Effect of variation of distance between patch and strip on bandwidth of proposed antenna

\begin{tabular}{|c|c|c|c|c|c|c|}
\hline $\begin{array}{c}\text { Patch and feed } \\
\text { distance (d) (mm) }\end{array}$ & 0.4 & 0.5 & 0.6 & 0.7 & 0.8 & 0.9 \\
\hline $\begin{array}{c}\text { Frequency range } \\
\text { (GHz) }\end{array}$ & $1.96-3.52$ & $1.98-3.54$ & $1.98-3.5$ & $2-3.52$ & $2-3.52$ & $2-3.54$ \\
\hline Bandwidth (\%) & 64.1 & 65.0 & 63.3 & 63.3 & 63.3 & 64.1 \\
\hline
\end{tabular}

\subsection{Effect of slot position (p)}

Rectangular slot is being introduced from center of the patch at a position of $10 \mathrm{~mm}$ to obtain maximum bandwidth. The slot position is varied from $8 \mathrm{~mm}$ to $13 \mathrm{~mm}$ in steps of $1 \mathrm{~mm}$. The optimized $\mathrm{S}_{11}$ parameter is being shown in the Fig. 4. The slot is being introduced in vertical direction to obtain a dual band frequency range. From Fig. 4, it is clear that the lower cut-off frequency of the geometry does not change but there is change in the upper cut-off frequency of the geometry. From Table 4, the optimum slot position having maximum bandwidth is obtained at $\mathrm{p}=10 \mathrm{~mm}$. 


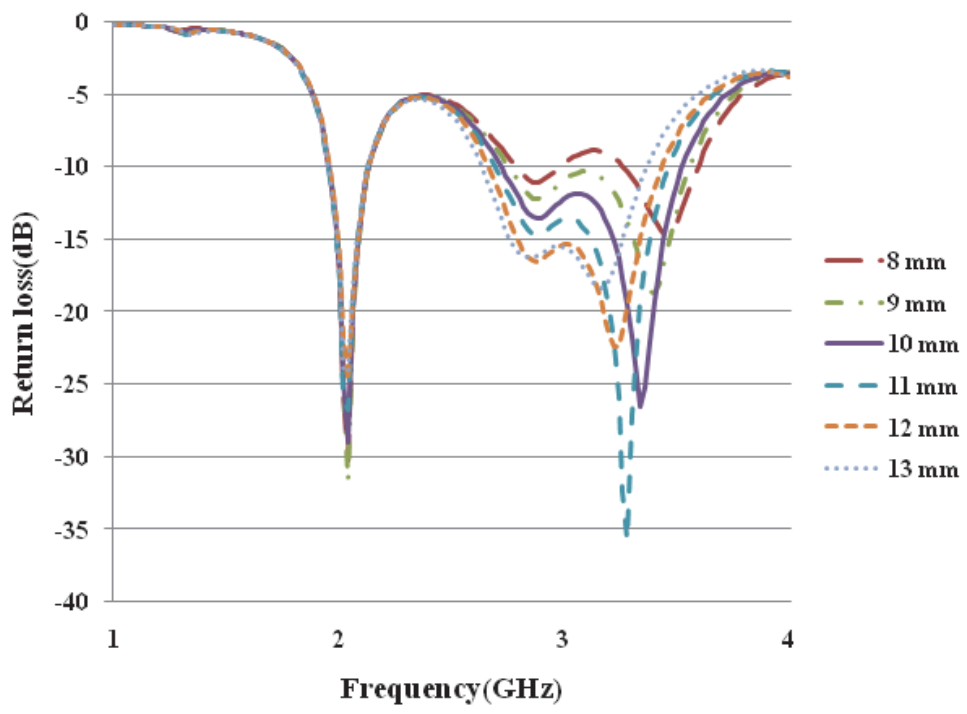

Figure 4. Return loss characteristics for different slot position

Table 4. Effect of variation of slot position on bandwidth of proposed antenna.

\begin{tabular}{|c|c|c|c|c|c|c|}
\hline $\begin{array}{c}\text { Slot position(p) } \\
\text { (mm) }\end{array}$ & 8 & 9 & 10 & 11 & 12 & 13 \\
\hline $\begin{array}{c}\text { Frequency } \\
\text { range(GHz) }\end{array}$ & $1.96-3.58$ & $1.96-3.54$ & $1.92-3.54$ & $1.96-3.46$ & $1.96-3.42$ & $1.96-3.36$ \\
\hline Bandwidth (\%) & 67.5 & 65.8 & 67.5 & 62.5 & 60.8 & 58.3 \\
\hline
\end{tabular}

\subsection{Effect of Slot Length (ls)}

Keeping all the above parameter constant, slot length is varied from $37 \mathrm{~mm}$ to $42 \mathrm{~mm}$ in steps of $1 \mathrm{~mm}$ each. The $S_{11}$ parameter of slot length variation is shown in Fig. 5. From Fig. 5, as we increase the length of the slot the upper cut-off frequency changes accordingly. As we increase the slot length above $41 \mathrm{~mm}$ the bandwidth of the antenna reduces as shown in the Table 5. The maximum bandwidth is obtained at the frequency range of 1.96-3.52 GHz which is $65 \%$. The optimum slot length is being obtained at $l_{S}=40 \mathrm{~mm}$ without the shift in the resonance frequency. 


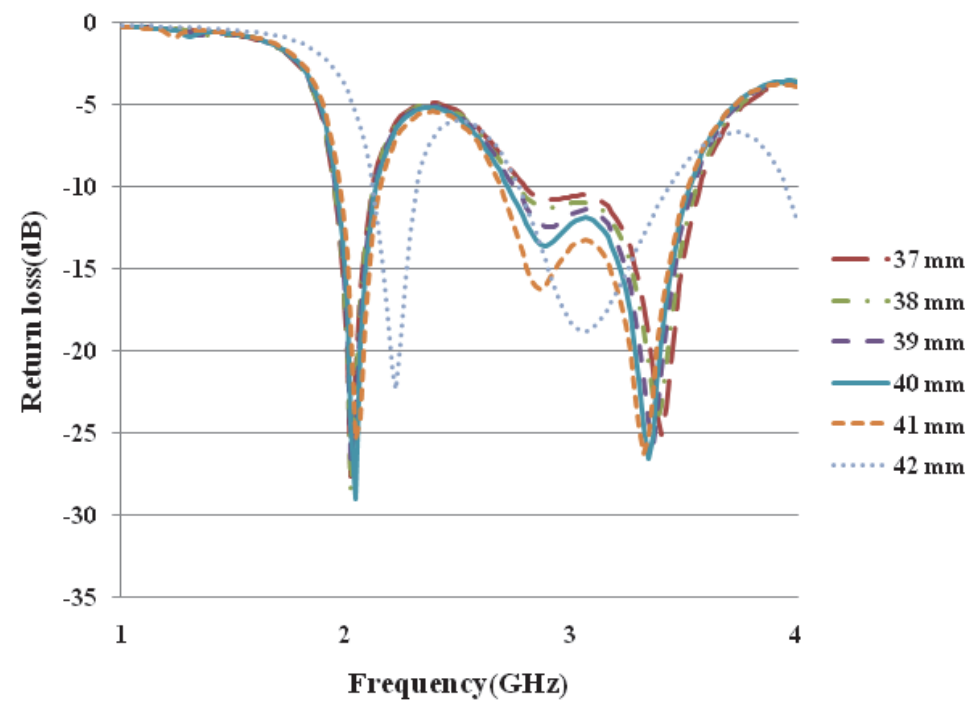

Figure 5. Return loss characteristics for different length of slot

Table 5. Effect of variation of slot length on bandwidth of proposed antenna.

\begin{tabular}{|c|c|c|c|c|c|c|}
\hline $\begin{array}{c}\text { Slot length }(\boldsymbol{l s}) \\
(\mathbf{m m})\end{array}$ & 37 & 38 & 39 & 40 & 41 & 42 \\
\hline $\begin{array}{c}\text { Frequency range } \\
(\mathbf{G H z})\end{array}$ & $1.96-3.51$ & $1.96-3.52$ & $1.96-3.5$ & $1.96-3.52$ & $1.98-3.5$ & $2.12-3.42$ \\
\hline Bandwidth (\%) & 64.6 & 64.6 & 64.2 & 65.0 & 63.3 & 54.2 \\
\hline
\end{tabular}

\subsection{Effect of slot width (ws)}

The slot width is being varied from $18 \mathrm{~mm}$ to $21 \mathrm{~mm}$ in steps of $1 \mathrm{~mm}$ keeping above parameter constant. The $S_{11}$ parameter change is shown in Fig. 6. From Fig. 6., it is clear that there is slight change in the upper and lower cut-off frequency of the proposed geometry. As $w s=22 \mathrm{~mm}$ shows for maximum depth in the return loss but there is slight shift in the resonance frequency of the antenna. From Table 6, it is being noted that the optimum slot width is obtained at $w s=20 \mathrm{~mm}$ without change in the resonance frequency having maximum bandwidth of $65 \%$. 


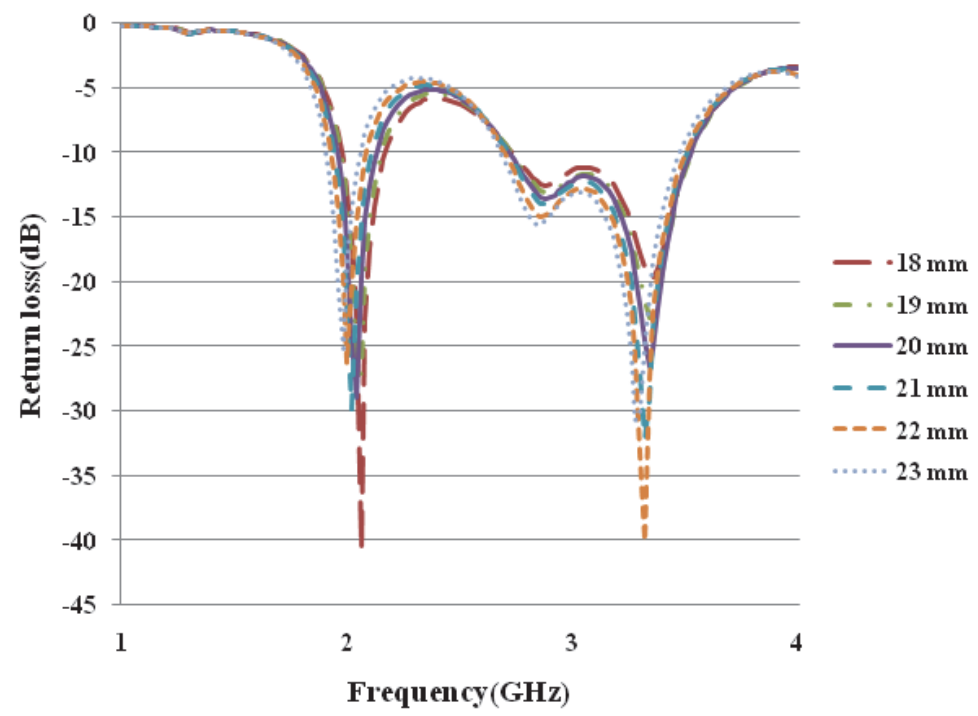

Figure 6. Return loss characteristics for different width of slot

Table 6. Effect of variation of slot width on bandwidth of proposed antenna

\begin{tabular}{|c|c|c|c|c|c|c|}
\hline $\begin{array}{c}\text { Slot width(ws) } \\
\text { (mm) }\end{array}$ & 18 & 19 & 20 & 21 & 22 & 23 \\
\hline $\begin{array}{c}\text { Frequency range } \\
\text { (GHz) }\end{array}$ & $1.98-3.52$ & $1.98-3.52$ & $1.96-3.52$ & $1.96-3.5$ & $1.94-3.5$ & $1.92-3.46$ \\
\hline Bandwidth (\%) & 64.2 & 64.2 & 65.0 & 64.2 & 65.0 & 64.2 \\
\hline
\end{tabular}

From all the cases studied, the optimum set of parameter are $d=0.5 \mathrm{~mm}, \mathrm{t}=1.5 \mathrm{~mm}$, $\mathrm{s}=10 \mathrm{~mm}$, along with slot parameter $\mathrm{p}=10 \mathrm{~mm}, l s=40 \mathrm{~mm}$ and $w s=20 \mathrm{~mm}$. As IE3D assumes infinite ground and substrate dimension the optimized geometry was resimulated using Ansoft HFSS v.13 [16]. Also, at both the resonant frequency, more than $5 \mathrm{~dB}$ gain was observed. Detailed studies of parameter have been conducted for various designs.

\section{Experimental Results and Discussions}

The prototype antenna with dimension listed in Fig. 1. with optimum parameter using IE3D presented in Table 1. was fabricated and tested. Return loss comparison is shown in Fig. 8.The substrate used for manufacturing is FR4 glass epoxy with dielectric constant of 4.4 and thickness $1.6 \mathrm{~mm}$ along with air gap of $7.5 \mathrm{~mm}$. The substrate is assembled above copper ground plane of dimension $100 \times 100 \times 1.6 \mathrm{~mm}^{3}$.A photography of the antenna is shown in the Fig. 7. Comparison of $S_{11}$ parameter can be seen in Fig. 8 . The pin of SMA connector is extended to reach the feed strip and is soldered there. 
From Fig. 8. it is clear that the proposed antenna has an operating frequency range at $2.4 \mathrm{GHz}$. The prototype antenna was tested for $\mathrm{S}_{11}$ using Agilent Technologies N9925A. From Fig. 9. it is clear that voltage standing wave ratio (VSWR) of the proposed antenna is below $2 \mathrm{~dB}$ at the operating frequency $2.4 \mathrm{GHz}$. The gain of antenna is above $5 \mathrm{~dB}$ at the operating frequency shown in Fig. 10. The measured gain fairly agrees with the stimulated gain of the proposed antenna.

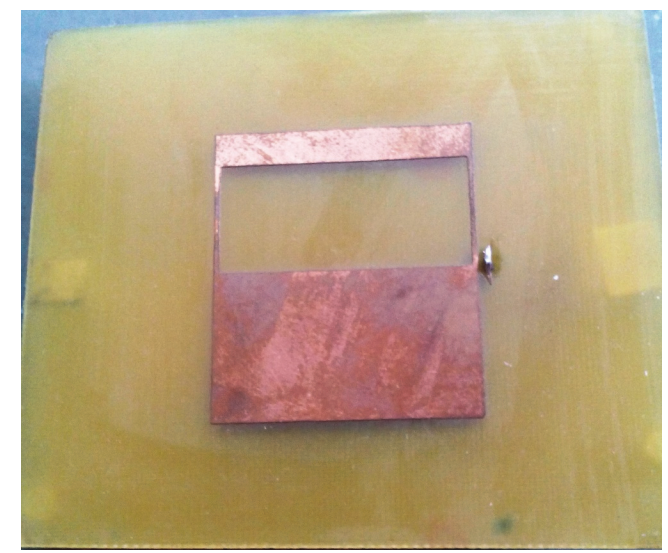

(a)

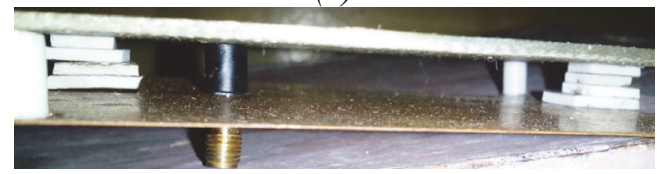

(b)

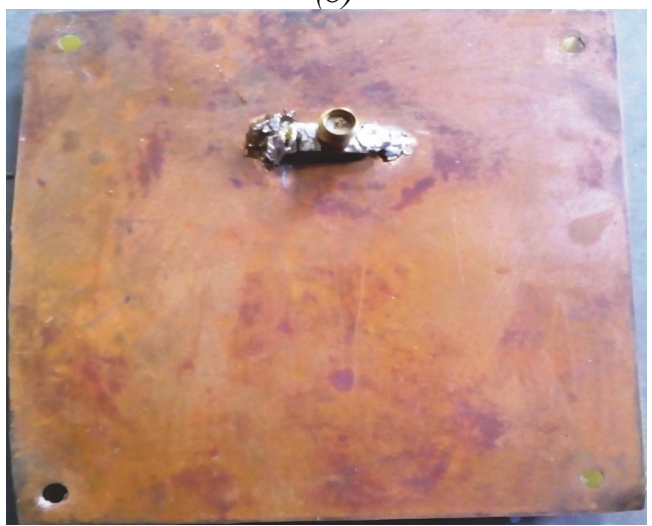

(c)

Figure 7. Fabricated prototype (a) Front side (b) Air Gap (c) Rear side 


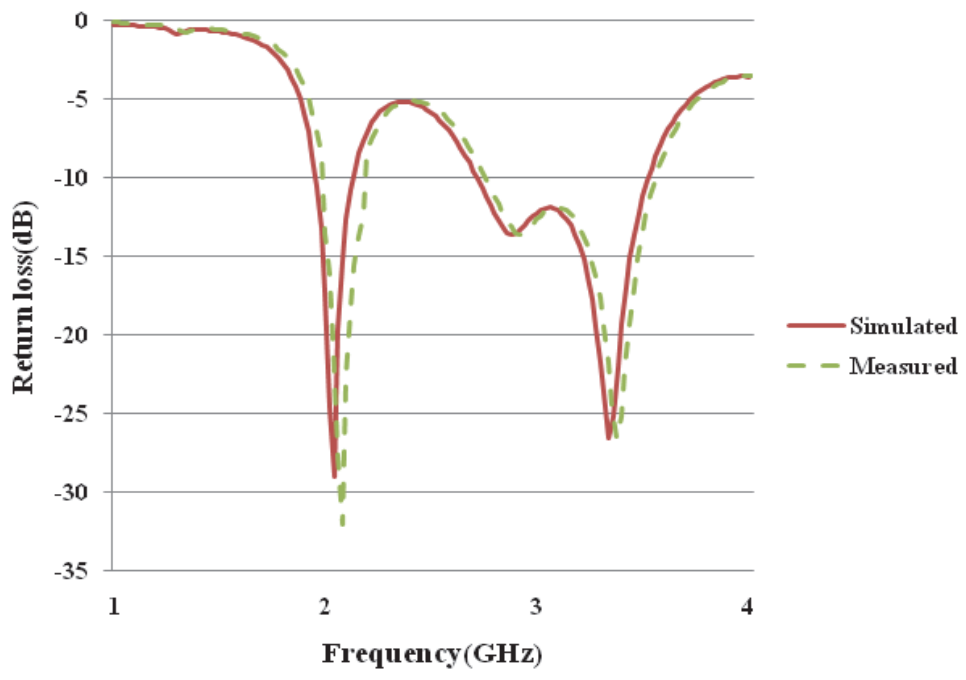

Figure 8. Return loss characteristics of antenna shown in Figure 1 with stimulated and measured results

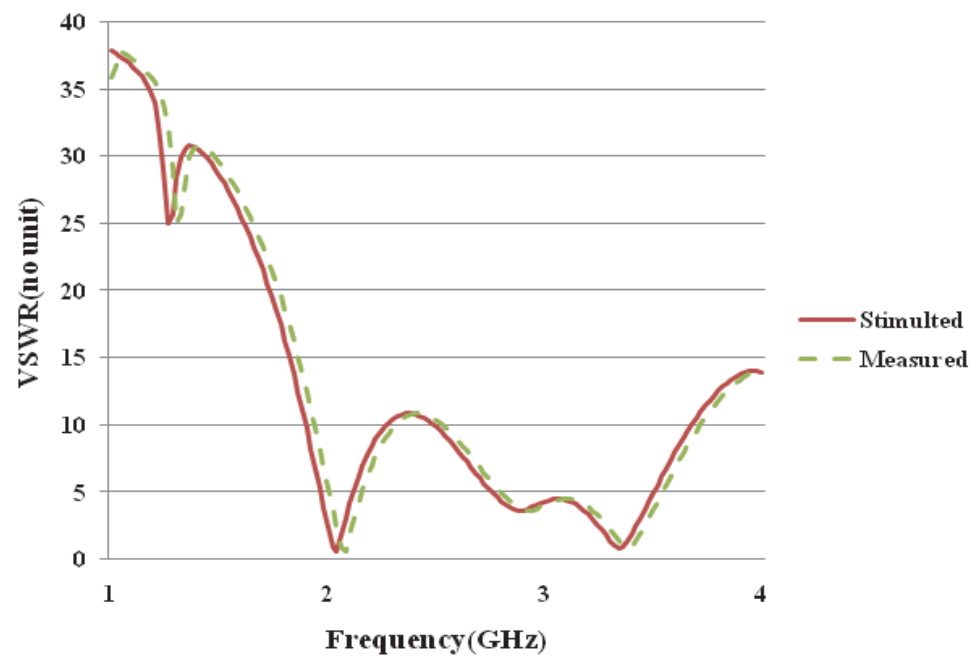

Figure 9. VSWR versus frequency of proposed antenna shown in Figure 1. 


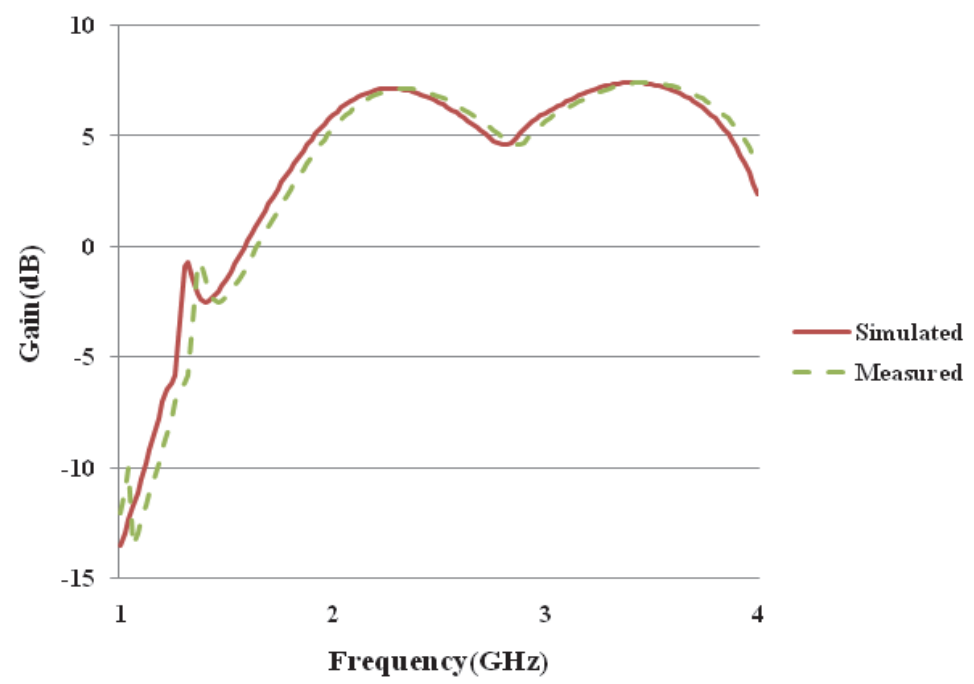

Figure 10. Gain versus frequency of proposed antenna shown in Figure 1.

\section{Conclusion}

Rectangular slot antenna for broadband application with a finite ground is being presented. By varying the slot length and width dual band frequency is being achieved. The antenna presented here offers impedance bandwidth of $5.83 \%$ and $33.3 \%$ in the frequency range of $1.96 \mathrm{GHz}$ to $2.1 \mathrm{GHz}$ and $2.72 \mathrm{GHz}$ to $3.52 \mathrm{GHz}$ respectively. The gain of the proposed antenna has value greater than $5 \mathrm{~dB}$. The proposed antenna is simple, easy to fabricate and need to investigate with less parameter. The antenna presented here is suitable for broadband applications.

\section{References}

[1] Kumar, G., Ray, K.P.: Broadband Microstrip Antenna, Artech House, 2003

[2] Balanis, C.A.: Antenna Theory, 2nd Edition, John Wiley \& Sons, Inc., 2004

[3] Dadime, G.M., Kasabegoudar, V.G.: A slotted circular monopole antenna for wireless applications, International Journal of wireless Communications and Mobile Computing, vol. 2, no. 2, pp. 30-34, 2014

[4] Kasabegoudar, V.G., Vinoy, K.J.: Coplanar Capacitively Coupled Probe Fed Microstrip Antennas For wideband Applications, IEEE Transactions On antennas and propagation, vol. 58, no. 10, pp. 3131-3138, 2010

DOI: $10.1109 /$ TAP.2010.2055781

[5] Subhanshu Verma, Preetam Kumar: Printed Egg Curved Slot Antenna for wideband Applications, Progress in Electromagnetic Research B, vol. 58, pp. 111121, 2014

DOI: $10.2528 /$ PIERB14010402 
[6] Yingying Tan, Liping Yan, Xiang Zhao, Changjun Liu, Kama Huang: Bandwidth Enhancement of a Printed Slot Antenna with a Diamond Shaped Tuning Stub, Progress in Electromagnetic Research C, vol. 50, pp. 87-93, 2014 DOI: 10.2528/PIERC14032404

[7] Jianjun Wu, Yingzeng Yin, Zedong Wang, Ruina Lian: Dual Band Circularly Polarized Antenna with Differential Feeding, Progress in Electromagnetic Research C, vol. 49, pp. 11-17, 2014 DOI: 10.2528/PIERC14030603

[8] Shaoshuai Zhang, He Huang, Yingzeng Yin: A Broadband CPW-Fed Circularly Polarized Square Slot Antenna For UHF RFID Application, Progress in Electromagnetic Research C, vol. 50, pp. 39-46, 2014 DOI: 10.2528/PIERC14021707

[9] Veeresh G. Kasabegoudar, Dibyant S. Upadhyay, K.J Vinoy: Design Studies of Ultra-Wideband Microstrip Antennas with Small Capacitive Feed, Hindavi Publishing Corporation International Journal of Antenna and Propagation, Article ID 67503, pp. 1-8, 2007 DOI: $10.1155 / 2007 / 67503$

[10] Wen-Chung Liu, Chao-Ming Wu, Yang Dai: Design of Triple Frequency Microstrip Fed Monopole Antenna usion Defected Ground Structure, IEEE Transactions On antennas and propagation, vol. 59, no. 7, pp. 2457-2463, 2011 DOI: 10.1109/TAP.2011.2152315

[11] G.F.Khodaei, J.Nourinia, C. Ghobadi: A Practical Miniaturized U-Slot Patch Antenna With Enhanced Bandwidth, Progress in Electromagnetic Research B, vol. 3, pp. 47-62, 2008 DOI: $10.2528 /$ PIERB07112201

[12] V.G.Kasabegoudar, K. J. Vinoy: A Broadband Suspended Microstrip Antenna For Circular Polarization, Progress In Electromagnetic Research, PIER 90, pp. 353368, 2009

[13] Sathiyamoorthy Murugan, Elamurugan Satish Kumar, Vayanaperumal Rajamani: Design and Analysis of Double Uslot Loaded Dual Frequency Microstrip Antenna, Progress In Electromagnetic Research C, vol. 45, 101-112, 2013 DOI: 10.2528/PIERC13090502

[14] V. G. Kasabegoudar: Dual Frequency Ring Antennas with Coplanar Capacitive Feed, Progress In Electromagnetic Research C, vol. 23, 27-39, 2011 DOI: 10.2528/PIERC11060104

[15] Ansoft High Frequency Structure Simulation (HFSS), Ver. 13, Ansoft Corporation, 2008

[16] IE3D simulation software, Zealand Software Inc., Ver. 14.05, CA, 2008 